\title{
A Critical Review of Effects of COPD Self-Management Education on Self-Efficacy
}

\author{
Michael Stellefson, Bethany Tennant, and J. Don Chaney \\ Department of Health Education and Behavior, University of Florida, P.O. Box 118210, Gainesville, FL 32611, USA \\ Correspondence should be addressed to Michael Stellefson, mstellefson@ufl.edu
}

Received 4 January 2012; Accepted 26 January 2012

Academic Editors: P. Bendtsen and K. M. Rospenda

Copyright ( $) 2012$ Michael Stellefson et al. This is an open access article distributed under the Creative Commons Attribution License, which permits unrestricted use, distribution, and reproduction in any medium, provided the original work is properly cited.

\begin{abstract}
Chronic obstructive pulmonary disease (COPD) causes progressive airflow limitation which results in prolonged episodes of coughing and shortness of breath. COPD self-management education (COPDSME) programs attempt to enhance patient selfefficacy for managing symptoms. The purpose of this paper was to conduct a critical literature review that identified peer-reviewed articles assessing the effects of COPDSME on self-efficacy outcomes. Seven articles were located after an exhaustive search. Most studies $(n=6)$ reported statistically significant improvements in self-efficacy following intervention. Almost all of the studies tested interventions that drew upon at least 2 recommended sources of efficacy information. Two studies specifically noted increased self-efficacy for controlling physical exertion following COPDSME. Within the reviewed studies, the content within each educational treatment varied widely and showed a lack of standardization, and the types of instruments used to assess selfefficacy varied. This paper highlights the need for more controlled trials that investigate potential between-subjects effects of different types of COPDSME programs on self-efficacy outcomes. Incorporating practice models for patient-centered primary care in COPD requires the use of tailored efficacy building strategies for specific self-management behaviors.
\end{abstract}

\section{Introduction}

Chronic obstructive pulmonary disease (COPD) is a preventable and treatable disease, characterized by progressive airflow limitation that is not fully reversible and is associated with an abnormal inflammatory response of the lung to noxious particles and/or gases [1]. Airway obstruction results in prolonged episodes of coughing and dyspnea (i.e., shortness of breath), exacerbations which can cause fear leading to avoidance of regular activity, causing additional deconditioning that can aggravate dyspnea even further [2]. COPD is now the third leading cause of death in the United States [3]. Accordingly, Healthy People 2020 objectives aim to reduce the proportion of adults whose activities are limited due to chronic lung and breathing problems, reduce COPD-related hospitalization rates and reduce COPD-related hospital emergency department visit rates [4].

Because pulmonary rehabilitation programs are delivered in an outpatient and/or hospital facility, various estimates suggest only $1-14 \%$ of patients with COPD are referred to these formal programs [5]. Due to the limited access and utilization, it is suggested that "pulmonary rehabilitation ... not stand as an isolated, albeit multidimensional intervention. It should be part of an integrated care process and include self-management support ... aiming to achieve a shift from management by the healthcare provider, to management by the patients themselves" [6, page 462]. COPD self-management refers to engaging in activities that promote adequate inhalation technique, build physiologic reserves and prevent adverse health outcomes, monitoring respiratory and emotional status and making appropriate management decisions on the basis of this selfmonitoring, and managing the deleterious effects of illness with prescribed coping skills [7]. While patients claim to be well informed about coping with COPD, actual knowledge of COPD self-management is limited [8]. For example, only 1/4 of patients with COPD have ever been told how to prevent a dyspnea exacerbation [9]. It has been suggested that this lack of awareness is related to the general absence of information available for COPD patients regarding social and 
behavioral dimensions of self-management [10]. Hernandez and colleagues [9] note that "clearly, better patient education regarding the prevention and management of [dyspnea] exacerbations is required" (page 1011). To date, psychosocial interventions aimed at improving COPD self-management have illustrated a lack of consensus regarding what particular skill development activities should be included in most COPD self-management education (COPDSME) programs $[10,11]$.

COPDSME programs can enhance self-efficacy, a fundamental intermediary objective for reducing health care utilization due to COPD exacerbations [6]. Effing and colleagues suggest that, "core-elements of behaviour change (e.g., enhancing self-efficacy (emphasis added) expectations or social support) should be implemented in the selfmanagement educational programmes" (page 12). Individuals with similar levels of physical impairment from COPD may achieve different levels of functional outcomes based on their level of self-efficacy. Enhanced self-efficacy is fundamental to promoting effective self-management and enabling behavior change in the long term [12], and is a quantifiable mediator between disease and unnecessary activity restriction [13]. Numerous studies of patients with COPD [13-19] have suggested the relationship between objective lung function and HRQoL is mediated by selfefficacy. Self-efficacy for coping with COPD has been to shown to affect self-reported HRQoL more so than measures of objective lung function $[15,17]$. High self-efficacy predicts reduced psychosocial impact of disease, improved physical activity levels, and increased HRQoL [20]. Conversely, low self-efficacy has been shown to predict poor self-management of COPD [21]. While greater self-efficacy is associated with effective COPD self-management, little is known about what particular sources of efficacy information influence COPD self-efficacy. Because we do not yet know whether COPD education (without formal self-management training) is sufficient to improve self-efficacy [22], it is important to investigate the impact various COPDSME programs have had on self-efficacy outcomes. The purpose of this study was to conduct a systematic literature review that identified articles which assessed effects of COPDSME on COPD self-efficacy.

1.1. Self-Efficacy Theory. Self-efficacy refers to one's confidence in their ability to control, organize, and execute a course of action required for performing specific tasks that will lead to certain outcomes [23]. Belief in one's efficacy to exhibit behavioral control is a common pathway through which psychosocial influences affect the adoption and maintenance of health behavior change [24]. Working in concert with the assumptions of human capability and expectancy [25], all cognitive and behavior change initiates through an individual's perceived self-efficacy [23]. Expectations about self-efficacy are based on four sources of information: (a) performance mastery experience, (b) vicarious experience or modeling, (c) emotional or physiological arousal, and (d) verbal persuasion [23].

Performance mastery (i.e., information derived from mastery of difficult tasks) is believed to be the most reliable source for self-efficacy expectations. It involves getting people actively involved in behavior change, by advocating the development and adoption of a specific action plan for achieving a specific goal [26]. Information gathered following the mastery of a task offers people assurance that the information is indeed reliable [23]. Social modeling, or vicariously experiencing an activity through observing or imitating a role model, is another important source of efficacy information. Role models who are perceived as similar to the learner have the greatest impact when delivering efficacy information, because model identification is strengthened by observing similar attributes portrayed by models [27]. It is preferable to illustrate models overcoming any obstacles associated with behavioral adaptations, as this portrayal has been shown to produce more positive influences on self-efficacy $[25,28]$. Self-efficacy information is also acquired through somatic indicators, such as physical and affective states, which can affect intentions to carry out health behaviors [23]. Physiological and emotional arousal and feedback can substantially influence self-efficacy. For example, positive biofeedback about exercise capacity can positively influence personal efficacy beliefs and outcome expectancies regarding physical activity limitations; while high physiological arousal (e.g., dyspnea, pain, and weakness) can diminish self-efficacy beliefs by impairing physical activity performance. A final source of self-efficacy information is gathered through verbal persuasion. This information is provided through verbally convincing an individual of their own ability to achieve their goals. Verbal persuasion can be the primary motivator for action or leveraged through advice which endorses sustained effort [29]. The persuader must be respected, knowledgeable, and provide information in a manner conducive to enhancing personal efficacy.

\section{Materials and Methods}

2.1. Search Procedures. This paper adopted the following definition of COPDSME: planned learning experiences aimed at helping patients actively utilize a support system to acquire personal knowledge and carry out skills related to COPD self-management, increase self-confidence in appropriate disease self-management decision making, and facilitate action to correctly self-manage disease complications [30, 31]. The experimental units of analysis for inclusion were peer-reviewed journal articles evaluating effects of COPDSME program activities on COPD self-efficacy. The educational elements included within each COPDSME program were recorded in an attempt to make associations between program activities and self-efficacy outcomes. Only the effects of treatment conditions that met the criteria for COPDSME were considered.

2.2. Data Sources. In order to generate a sample of empirical studies, an exhaustive search of electronic databases was conducted. The searched databases included: EBSCO, ERIC, PsychINFO, MEDLINE, EMBASE, MasterFILE Premier, Academic Search Complete, CINAHL Plus with Full Text, 
Applied Social Sciences Index and Abstracts, Cambridge, and CSA. Bandura initially described self-efficacy in 1977; therefore, all manuscripts were published from 1977 until December 2010 (time of search). The key terms were entered in various combinations with multiple Boolean operators, and included: COPD, chronic obstructive pulmonary disease, chronic airflow obstruction, obstructive lung disease, emphysema, chronic bronchitis, self-management, selfmanagement education, self-care, self-efficacy, mastery, and literature review. Following the database search, the investigators conducted hand searches (i.e., manual method of searching and scanning print journals for research articles) of reference lists within each article.

2.3. Inclusion Criteria. Within the systematic literature search, the following inclusion criteria were applied:

(1) any randomized cross-sectional, case-control, or longitudinal study assessing the effects of at least one COPDSME program activity;

(2) measurement of self-efficacy using survey instruments during and/or following COPDSME program participation;

(3) male and/or female patients with COPD above the age of 40 who participated in COPDSME program activities as defined above;

(4) patients described as being clinically diagnosed with COPD (e.g., $\mathrm{FEV}_{1} / \mathrm{FVC}<0.7$ ).

2.4. Exclusion Criteria. Within the systematic literature search, the following exclusion criteria were applied:

(1) studies that assessed self-efficacy as an outcome among COPD patients, with no COPSME activities included and described;

(2) educational interventions targeted for patients with multiple comorbidities outside of COPD.

2.5. Data Extraction. The investigators independently assessed the titles and abstracts of all identified citations. Each of the reviewers recorded each citation as being "acceptable" or "unacceptable" based on set forth inclusion and exclusion criteria. The ratings of each investigator were then recorded and compared. For each manuscript in question, the full text of the paper was evaluated and a definitive agreement was made as to the inclusion or exclusion of each article in question based on consensus agreement. When consensus could not be met, an additional colleague was consulted to contribute an extra expert opinion. Based on this selection procedure, final decisions were made regarding which studies to include and exclude from the systematic review.

2.6. Measurement of COPD Self-Efficacy. Various scales were used in the reviewed studies to assess self-efficacy among patients. The 34-item COPD Self-Efficacy Scale (CSES) specifically assesses self-efficacy in individuals with COPD. This measure has demonstrated good test-retest reliability $(r=0.77)$, excellent internal consistency $(\alpha=$ 0.95 ), and a five-factor structure (negative affect, intense emotional arousal, physical exertion, weather/environments, and behavioral risk factors). The Self-Efficacy for Managing Shortness of Breath scale (SEMSOB) is a single-item instrument that measures patients' overall confidence in keeping shortness of breath in check during activities of daily living. The SEMSOB has demonstrated adequate testretest reliability $(r=0.77)$ and construct validity [32]. The Self-Efficacy for Walking Questionnaire (SE-W) has demonstrated evidence of construct validity, with higher scores reflecting more confidence when walking [33].

Additionally, the self-efficacy dimension of the SelfManagement Ability Scale (SMAS) has also been used [34]. This subscale of the SMAS consists of five items each of which are rated on a 6-point scale, with a higher total score indicating greater self-efficacy. Reliability measures were not reported for data collected using the SE-W and SMAS. Finally, the Self-Efficacy for Managing Chronic Disease-6 (SEMCD-6) item scale was used. The SEMCD-6 [35] is a six-item scale that measures self-efficacy to manage chronic disease. Scores on this scale are computed as the mean of the six items, each measured on Likert scales ranging from 1 (not at all confident) to 10 (totally confident). Reliability measures for the SEMCD-6 have been high $(\alpha=0.91)$ [35] and testretest reliability have been reported as statistically significant $(r=0.87)[32]$.

\section{Results}

All articles gathered through the initial search and screen process $(n=305)$ were evaluated for inclusion in the sample pool. Two hundred twenty (220) records were excluded after the screen of titles and abstracts. The primary reason for the initial exclusion included lack of self-efficacy measurements during or following exposure to COPDSME interventions. In addition to the 85 papers that remained after the initial exclusion, 11 other articles were identified as meeting criteria for a full text assessment by hand searches which occurred following a scan of the reference sections of each databaseidentified article to enhance the breadth of the examination. Overall, 96 papers were included in this full text assessment, of which 89 were excluded for a variety of reasons listed and described in Figure 1. Seven $(n=7)$ articles were left describing empirical studies assessing COPD self-efficacy among patients participating in COPDSME interventions. Four studies were carried out in the United States, one in Hong Kong, one in Turkey, and one in central Netherlands.

Table 1 describes the design characteristics of all reviewed studies. Study characteristics described here include: assessment instruments used in each study, the reliability of data collected using survey instruments (described above), and the data analyses used to determine study results. Results of the seven reviewed studies are discussed below according to survey instrument that was used to assess COPD self-efficacy.

3.1. DataSynthesis. This systematic review demonstrated that most studies $(85.7 \%)$ showed statistically significant 


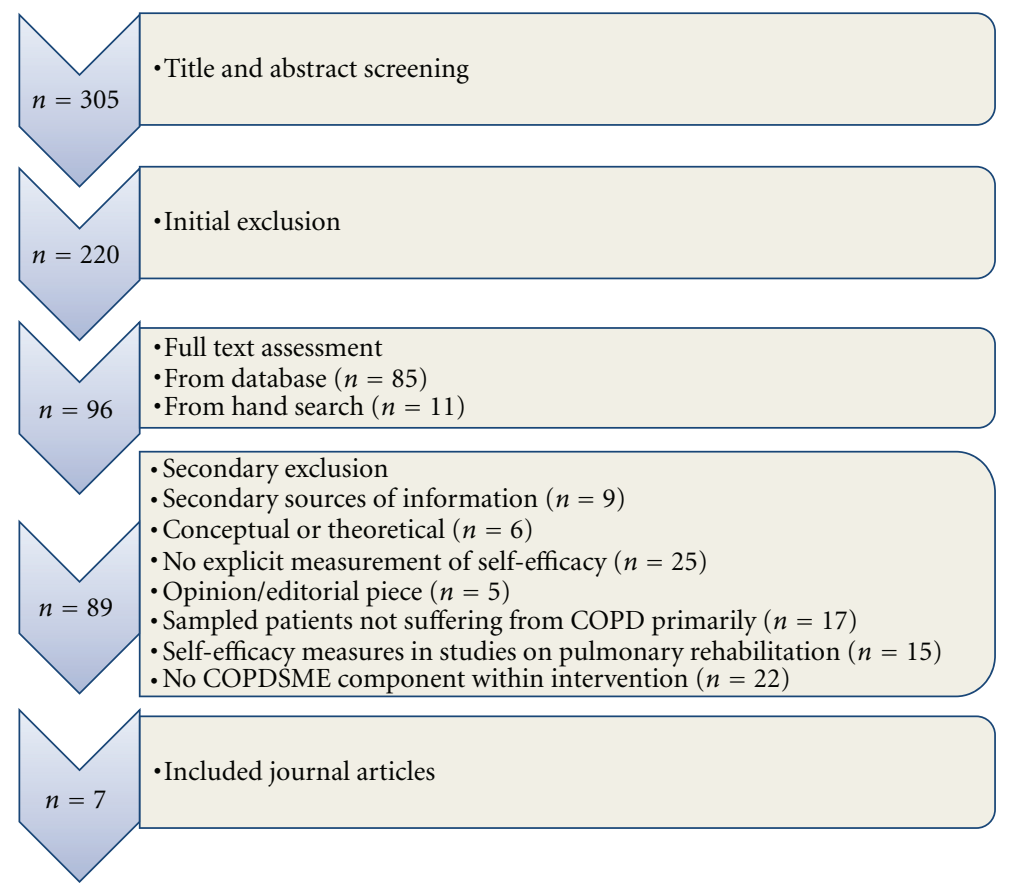

FIGURE 1: Flow diagram of systematic literature search process.

TABLE 1: Characteristics of reviewed studies.

\begin{tabular}{|c|c|c|c|c|c|}
\hline Author & Sample size $(n)$ & Design & Instrument & Instrument reliability & Primary data analysis \\
\hline Davis et al. [36] & 102 & RCT & SE-W; SEMSOB & $\begin{array}{l}\text { Not reported for study } \\
\text { data }\end{array}$ & $\begin{array}{l}\text { Two-way repeated } \\
\text { measures ANOVA }\end{array}$ \\
\hline $\begin{array}{l}\text { Donesky-Cuenco et al., } \\
\text { [37] }\end{array}$ & 103 & $\begin{array}{l}\text { Secondary Data } \\
\text { Analysis of RCT }\end{array}$ & SE-W; SEMSOB & $\begin{array}{l}\text { Not reported for study } \\
\text { data }\end{array}$ & $\begin{array}{l}\text { Two-way repeated } \\
\text { measures ANOVA }\end{array}$ \\
\hline Kara and Asti [38] & 60 & RCT & $\begin{array}{l}\text { Adapted CSES } \\
\text { (Turkish) }\end{array}$ & $\begin{array}{l}\alpha=0.94(\text { total) } ; 0.89 \\
0.80,0.73,0.75 ; 0.64 \\
\text { (subscales) }\end{array}$ & $\begin{array}{l}\text { Repeated measures } \\
\text { ANOVA }\end{array}$ \\
\hline Lemmens et al. [39] & 189 & Quasi-experimental & SMAS & $\begin{array}{l}\text { Not reported for study } \\
\text { data }\end{array}$ & Paired sample $t$-tests \\
\hline Scherer et al. [40] & 59 & $\begin{array}{l}\text { Two-group, } \\
\text { pretest-posttest }\end{array}$ & CSES & $\begin{array}{l}\text { Not reported for study } \\
\text { data }\end{array}$ & Paired $t$-tests \\
\hline Stellefson at al. [41] & 41 & $\begin{array}{l}\text { Multiple group, } \\
\text { pretest-posttest }\end{array}$ & $\begin{array}{l}\text { SEMCD-6; } \\
\text { SOLQ-Coping }\end{array}$ & SEMCD-6 $(\alpha=.97)$ & $\begin{array}{l}\text { Multivariate analysis of } \\
\text { covariance } \\
\text { (MANCOVA) }\end{array}$ \\
\hline Wong et al. [42] & 60 & RCT & $\begin{array}{l}\text { Adapted CSES } \\
\text { (Chinese) }\end{array}$ & Test-retest $(r=0.88)$ & Mann-Whitney $U$-tests \\
\hline
\end{tabular}

RCT: Randomized Control Trial; SE-WALK: Self-Efficacy for Walking Questionnaire; SEMSOB: Self-Efficacy for Managing Shortness of Breath; SMAS: Self-Management Ability Scale; SEMCD-6: Self-Efficacy for Managing Chronic Disease, 6-item scale; SOLQ-Coping: Seattle Obstructive Lung Disease Questionnaire-Coping; CSES: COPD Self-Efficacy Scale.

improvements in COPD self-efficacy following self-management education. Table 2 provides a synopsis of the main findings generated from each reviewed study. Specifically, two studies $[40,42]$ noted increased confidence specifically with regard to controlling physical exertion experienced during activities of daily living (e.g., climbing stairs too fast, getting up too quickly, rushing to accomplish household chores, etc.). The only study which failed to show any notable changes in self-efficacy following COPDSME intervention was a quasi-experimental (noncontrolled) study [39]. Even still, this study showed no deleterious effect on self-efficacy over the 12-month study time period. In all of the reviewed studies, self-efficacy was assessed over a period no longer than 12 months after intervention.

3.2. Educational Interventions. The modes of education varied, with two studies implementing strictly didactic education in a group setting, two studies using a combination of didactic and individualized education, two studies using interactive meetings with individual patients, and 
TABle 2: Main findings from each reviewed study.

\begin{tabular}{|c|c|}
\hline Author (citation) & Main findings \\
\hline Davis et al. [36] & $\begin{array}{l}\text { (i) Participants who completed an education program with a prescribed walking regimen } \\
\text { exhibited greater self-efficacy for walking. } \\
\text { (ii) No improvement in self-efficacy for managing shortness of breath was found after } \\
\text { treatment when measuring the construct using the COPD Self-Efficacy Scale (CSES); } \\
\text { however, a statistically significant effect was found when measuring self-efficacy using the } \\
\text { Self-Efficacy for Managing Shortness of Breath (SEMSOB). } \\
\text { (iii) Participants exposed to an education program with a prescribed walking regimen } \\
\text { revealed improvements in self-efficacy without participation in structured exercise } \\
\text { regimens. }\end{array}$ \\
\hline Donesky-Cuenco et al. [37] & $\begin{array}{l}\text { (i) Statistically significant improvements in self-efficacy for walking found at } 4 \text { and } 12 \\
\text { months, but not present at } 8 \text { months. } \\
\text { (ii) Self-efficacy for managing shortness of breath improved at } 4 \text { and } 8 \text { months, but the } \\
\text { significant effect disappeared at } 12 \text { months. }\end{array}$ \\
\hline Kara and Asti [38] & $\begin{array}{l}\text { (i) Within-group improvements in self-efficacy shown to vary slightly between the } \\
\text { experimental and control group, with the self-efficacy enhancement effect diminishing } \\
\text { over time for the control group but lasting for the experimental group exposed to the } \\
\text { structured education. }\end{array}$ \\
\hline Lemmens et al. [39] & $\begin{array}{l}\text { (i) Group exposed to education showed no statistically significant change in self-efficacy } \\
\text { over a } 12 \text {-month period, with mean scores on self-efficacy remaining stable throughout } \\
\text { the study. }\end{array}$ \\
\hline Scherer et al. [40] & $\begin{array}{l}\text { (i) Statistically significant improvement in total self-efficacy from baseline to one month } \\
\text { following implementation of the educational intervention. } \\
\text { (ii) Statistically significant improvement in self-efficacy for controlling physical exertion } \\
\text { from baseline to six months following intervention. } \\
\text { (iii) No statistically significant differences in total self-efficacy found at 6-month } \\
\text { followup. }\end{array}$ \\
\hline Stellefson et al. [41] & $\begin{array}{l}\text { (i) Participants receiving a pamphlet reported higher self-management self-efficacy than } \\
\text { those receiving a DVD and especially greater than that those receiving both educational } \\
\text { treatments (DVD + pamphlet) concomitantly. }\end{array}$ \\
\hline Wong et al. [42] & $\begin{array}{l}\text { (i) Participants in telephone education intervention showed statistically significant } \\
\text { improvement total self-efficacy, yet revealed no corresponding significant effects on any } \\
\text { subscales, except for physical exertion. }\end{array}$ \\
\hline
\end{tabular}

one study providing individualized educational materials to patients. Table 3 describes the educational delivery strategy, the educational content included within each intervention, and the extent (e.g., duration of session plus intervention time period) of the instructional interaction with patients. The content included within each intervention was variable; yet, the most often included self-management topics were proper breathing techniques $(n=5)$, physical activity $(n=$ $3)$, nutrition $(n=4)$, and smoking cessation $(n=1)$. In addition, the methods used within each intervention to increase self-efficacy are reported in Table 4. All of the studies except one [39] described intervention activities that drew upon at least 2 recommended sources of efficacy information. The length of time for each intervention also ranged widely, with interventions occurring anywhere from less than one month to up to 12 months $(\mathrm{M}=4.68$ months, $\mathrm{SD}=5.06$ months).

3.3. Intervention Response Measured by CSES. Scherer et al. (1998) [40] conducted a study of COPD patients to determine the effects of two intervention strategies on selfefficacy expectations for managing breathing difficulty. A nonexperimental, two group preposttest design $(n=59)$ was utilized to compare a program that offered only selfmanagement education with a pulmonary rehabilitation program that combined education and exercise training. Participants' self-efficacy was measured at baseline, one month and then six months following intervention. Paired $t$-test analyses revealed that participants in the educationonly program showed a significant improvement in total CSES scores from baseline to one month follow-up (mean difference $=0.33 ; P=.05)$. The analysis comparing baseline scores with those measured six months following intervention showed improvement in self-efficacy only in the domain of physical exertion (paired $t$-test $=-2.11 ; P=$ .047); however, no significant differences in total CSES score were found when comparing pretest scores with 1-month (mean difference $=0.18 ; P=.15$ ) and 6-month followup (no mean difference reported; $P=.265$ ). It should be noted that multiple paired $t$-tests increased the probability of experimentwise error by testing an excess number of pairwise hypotheses [43]. For this particular research design, it would have been advisable to conduct repeated measures analysis of variance (ANOVA) to limit the number of hypotheses 
TABLE 3: COPDSME delivery mode, content, and duration of instruction.

\begin{tabular}{|c|c|c|c|}
\hline Reviewed study & Delivery mode & Content & Length of education \\
\hline Davis et al. [36] & $\begin{array}{l}\text { Dyspnea self-management } \\
\text { education }(\mathrm{DME})+\text { individualized } \\
\text { walking plan }\end{array}$ & $\begin{array}{l}\text { Walking, purse lipped breathing, } \\
\text { diaphragmatic breathing, measure } \\
\text { breathlessness and heart rate }\end{array}$ & 8 weeks \\
\hline $\begin{array}{l}\text { Donesky-Cuenco et } \\
\text { al. [37] } \\
\text { (secondary data } \\
\text { analysis from Davis et } \\
\text { al. [36]) }\end{array}$ & $\begin{array}{l}\text { Dyspnea self-management } \\
\text { education }(\mathrm{DME})+\text { individualized } \\
\text { walking plan }\end{array}$ & $\begin{array}{l}\text { Walking, measure breathlessness } \\
\text { and heart rate }\end{array}$ & 12 months \\
\hline Kara and Asti [38] & Group education & $\begin{array}{l}\text { Breathing techniques, coughing } \\
\text { techniques, relaxation, medication, } \\
\text { diet, exercise }\end{array}$ & $\begin{array}{l}4 \text { weeks of } 3-4 \text { sessions } \\
\text { per week for about } \\
35-40 \text { min each session }\end{array}$ \\
\hline Lemmens et al. [39] & $\begin{array}{l}\text { Practice nurse meetings with } \\
\text { patients }\end{array}$ & $\begin{array}{l}\text { Smoking behavior, medication } \\
\text { usage, nutrition, and physical } \\
\text { activity }\end{array}$ & $\begin{array}{l}\text { At least } 15 \text { minute } \\
\text { meetings over a } \\
12 \text {-month period }\end{array}$ \\
\hline Scherer et al. [40] & $\begin{array}{l}\text { Classes conducted by a clinical } \\
\text { nurse specialist }\end{array}$ & $\begin{array}{l}\text { Pathophysiology of COPD, } \\
\text { nutrition, self-care instruction, } \\
\text { purse lipped breathing, } \\
\text { diaphragmatic breathing }\end{array}$ & $\begin{array}{l}1 \text { hour, } 3 \text { times a week } \\
\text { for } 12 \text { weeks }\end{array}$ \\
\hline Stellefson et al. [41] & $\begin{array}{l}\text { DVD OR Pamphlet OR DVD + } \\
\text { Pamphlet }\end{array}$ & $\begin{array}{l}\text { COPD knowledge, action steps } \\
\text { following a diagnosis, seeking } \\
\text { medical attention, breathing } \\
\text { techniques when stationary and } \\
\text { moving, infection detection, } \\
\text { nutrition }\end{array}$ & $\begin{array}{l}\sim 30 \text { min DVD or } 4 \text {-page } \\
\text { pamphlet reviewed } \\
\text { individually over } 2 \\
\text { months }\end{array}$ \\
\hline Wong et al. [42] & $\begin{array}{l}\text { Telephone counseling by respiratory } \\
\text { nurse }\end{array}$ & $\begin{array}{l}\text { Patient dependent but including } \\
\text { energy saving and breathing } \\
\text { techniques, medication } \\
\text { management, relaxation techniques }\end{array}$ & $\begin{array}{l}\text { Two calls over a } 20 \text {-day } \\
\text { period }\end{array}$ \\
\hline
\end{tabular}

TABLE 4: Sources of efficacy information used in the review studies.

\begin{tabular}{|c|c|c|c|c|}
\hline Reviewed study & $\begin{array}{c}\text { Performance mastery } \\
\text { experience }\end{array}$ & $\begin{array}{c}\text { Vicarious } \\
\text { experience/modeling }\end{array}$ & $\begin{array}{c}\text { Emotional or } \\
\text { physiological arousal }\end{array}$ & $\begin{array}{c}\text { Verbal } \\
\text { persuasion }\end{array}$ \\
\hline Davis et al. [36] & $\checkmark$ & $\checkmark$ & $\checkmark$ & $\checkmark$ \\
\hline Donesky-Cuenco et al. [37] & $\checkmark$ & $\checkmark$ & $\checkmark$ & $\checkmark$ \\
\hline Kara and Asti [38] & $\checkmark$ & $\checkmark$ & $\checkmark$ & $\checkmark$ \\
\hline \multicolumn{5}{|l|}{ Lemmens et al. [39] } \\
\hline Scherer et al. [40] & $\checkmark$ & $\checkmark$ & $\checkmark$ & $\checkmark$ \\
\hline Stellefson et al. [41] & & $\checkmark$ & & $\checkmark$ \\
\hline Wong et al. [42] & $\checkmark$ & & $\checkmark$ & $\checkmark$ \\
\hline
\end{tabular}

being tested and decreasing the probability of a Type I error.

Kara and Asti [38] conducted an experimental study to assess the effect of coordinated education on self-efficacy expectations in patients with COPD. Sixty patients at an outpatient clinic were randomly assigned to an experimental group receiving four weeks of structured education while the control group was only offered educational advice at an initial meeting. Participants' self-efficacy was measured at baseline, 1-month (immediately following the program), and at 2-month using an adapted version of the Turkish CSES. To assess the difference in self-efficacy, two separate repeated measures analyses of variance (ANOVAs) were conducted assessing self-efficacy in both the control and experimental groups. For the control group, there was a significant improvement between baseline and 1-month (mean difference $=-0.31 ; P=.001)$, and between baseline and 2-month followup (mean difference $=-0.21 ; P=.002$ ); however, there was no significant improvement between 1-month and 2-month followup across any of the 5 dimensions of selfefficacy as measured by the CSES (mean difference $=-0.10$; $P=.074$; total scores). For participants in the experimental group, however, there was a significant improvement in total CSES scores on all 3 measurement occasions (mean difference $=-.21$ to $-1.15 ; P<.001)$. Moreover, withingroup improvements in self-efficacy was shown to vary slightly between the experimental and control group, with the self-efficacy enhancement effect diminishing over time 
for the control group but lasting for the experimental group exposed to the structured education.

Wong et al. [42] examined the effects of a nurse-initiated telephone follow-up intervention on self-efficacy among COPD patients. One of the aims of this randomized controlled trial sought to determine whether a nurse-led telephone follow-up program could increase the self-efficacy of patients managing dyspnea. Sixty patients with COPD were recruited from a hospital in Hong Kong and were randomly assigned to an intervention group that received an individualized educational and telephone support followup program $(n=30)$ or a control group receiving usual care $(n=30)$. Both groups completed a pre and posttest that included an adapted Chinese version of the CSES. Data analysis using the Mann-Whitney $U$-test determined group differences in the subscales and total scores on the Chinese CSES. Findings indicated statistically significant improvement on the total scores of the adapted Chinese CSES among, with no corresponding significant effects found on any of the subscales, except for improvement in physical exertion $(P=.001)$.

Davis et al. [36] published a randomized clinical trial undertaken to determine the effect of three types of interventions on self-efficacy to manage dyspnea in COPD patients. One-hundred and two participants received one of three self-management interventions designed to enhance the primary sources of self-efficacy information. One of the three interventions consisted of a dyspnea self-management education program that lasted 3 hours and was coupled with an individualized home-walking prescription. A repeated measured ANOVA was used to assess the effect of treatment (three interventions) and time (2 months) on each of four dependent variables at pre and posttest. For a multiple group, pretest-posttest design with random assignment (testing multiple dependent variables), it is suggested that a multivariate analysis of covariance (MANCOVA) on posttest scores be conducted, with pretest scores used as the covariate(s) $[37,44]$. Nevertheless, participants who completed the education program and received the prescribed walking regimen exhibited greater self-efficacy for walking $(P<$ $.0005)$. This significant treatment effect mirrored significant effects found in the two other pulmonary rehabilitation conditions. However, no improvement in disease-specific self-efficacy was found after treatment.

3.4. Intervention Response Measured by Other Scales. Davis et al. [36] showed a statistically significant effect when measuring self-efficacy using the SEMSOB $(P<.0005)$ at 2 months following intervention. To determine whether improvements in self-efficacy persisted after 2 months, Donesky-Cuenco and colleagues [37] extended the work of Davis et al. [36] by conducting a secondary data analysis by following up on patients participating in the former study. Univariate repeated measures analysis of variance (ANOVA) was used to assess the effect of treatment on two dependent variables (SE-W and SEMSOB) at three points measurement occasions $(4,8$, and 12 months). While the choice of data analysis technique could have been multivariate (e.g., MANOVA) to consider the two distinct types of self-efficacy under study
$[44,45]$, there were statistically significant improvements in SE-W found at 4 and 12 months, yet was not apparent at 8 months. Interestingly, self-efficacy for managing dyspnea, as measured by the SEMSOB improved at 4 and 8 months but disappeared at 12 months.

Lemmens et al. [39] conducted a quasi-experimental, one-group preposttest study that evaluated the effect of a patient education intervention designed to increase patients' understanding of COPD self-management strategies. Participants in this study were taught self-management strategies and given information booklets during multiple 15-minute contacts over a 12-month period (number of contacts per patient not specified). Self-efficacy was measured among 189 patients using the self-efficacy dimension of the SMAS [34]. Comparisons between baseline and 12-month self-efficacy outcomes were done using a paired $t$-test analysis. Results showed no statistically significant change in self-efficacy over the 12 -month period $(P=.865)$, with mean scores remaining almost precisely stable throughout the duration of the intervention [pretest: $4.24( \pm 0.74)$; posttest: 4.23 $( \pm 0.78)]$.

Stellefson et al. [41] conducted a multiple-group, pretestposttest study to test the effects of three educational treatments (DVD versus Pamphlet versus DVD + Pamphlet) on multiple health-related outcomes, including self-efficacy. Self-efficacy was measured using the SEMCD-6 [35]. Nontrend orthogonal planned contrasts (pairwise and complex) were tested comparing the effectiveness of viewing and reviewing a DVD (group 1) and pamphlet (group 2) exclusively versus distributing both interventions concurrently (group 3). A multivariate analysis of covariance determined the effect of instructional strategy on SEMCD-6 scores, with pretest SEMCD-6 scores adjusting for initial differences among treatment groups on the outcome measures. At posttest, contrast analyses revealed that when comparing the DVD to the Pamphlet group and the DVD + Pamphlet group to the DVD and Pamphlet group considered together, there were statistically significant differences on SEMCD-6 scores $(P=.001$ and $P<.001$, resp.). Interestingly, participants receiving a Pamphlet reported higher self-management selfefficacy (adjusted mean centroid $=7.15$ ) than those receiving a DVD (adjusted mean centroid $=5.10$ ) and especially greater than that those receiving both educational treatments concomitantly (adjusted mean centroid $=3.35$ ).

\section{Discussion}

4.1. Main Findings. This systematic review demonstrated that most studies ( $n=6$ or $85.7 \%$ ) showed statistically significant improvements in COPD self-efficacy following self-management education. Specifically, two studies [40, 42] noted increased confidence for controlling physical exertion experienced during activities of daily living (e.g., climbing stairs too fast, getting up too quickly, rushing to accomplish household chores, etc.). There was a limited follow-up postintervention to examine these outcomes longitudinally. Several reviewed studies collected data at various time points post intervention in an attempt to determine lasting effects of COPDSME interventions on self-efficacy over 
time [36-38]. Findings from these studies were inconsistent. The modes of education used in each intervention varied with unstandardized content covered in different studies. However, the topics included in each intervention, while variable, did draw upon the four sources of self-efficacy explicated by Bandura.

4.2. Implications for Building COPD Self-Efficacy. This systematic review does not provide clear evidence regarding what particular educational elements are important to improve self-efficacy; however, two studies specifically noted increased self-efficacy for controlling physical exertion experienced during ADLs. There do exist guidelines (albeit vague) noting important self-management topics to include within COPDSME programs $[46,47]$. These topics include information on medication use, proper nutrition, operation of inhalation devices, and performance of rehabilitative breathing techniques. However, little theoretical guidance exists related to which sources of self-efficacy information are important for creating self-confidence for these types of self-management skills and behaviors. For example, coordinated learning experiences informed by principles of selfregulation (i.e., self-monitoring, goal setting, feedback, selfreward, self-instruction, and enlistment of social support), a core tenet of social cognitive theory [23], may be especially appropriate for COPDSME interventions.

This paper further highlights the need for more randomized controlled trials that investigate between-subjects effects of different, sociocognitive, and behavioral theorybased COPDSME programs with long-term followup. In order to determine the impact and dose of COPSME needed to support COPD self-efficacy, guided self-management interventions that include specified amounts of performance mastery, social modeling, efficacy information, and verbal persuasion are warranted. Once a clear idea of efficacy enhancing educational approaches is better understood, it will be important to determine how often instructional strategies need to be delivered to procure and strengthen efficacy beliefs and standardize patient-centered outcomes.

The nature of the educational experiences provided to patients was variable, making replication of best-practice COPDSME interventions an ambiguous task. Patients may respond better to consistent educational experiences over time rather than sporadic (perhaps conflicting) pieces of information provided at periodic patient visits, which may cause contradiction and/or confusion. One study outside the scope of the present paper found that using audiovisual based technologies over time offered a stabilizing effect for the clinical progression of COPD and also positively impacted HRQoL [48]. It is important that patients are taught to self-manage their disease, rather than told to learn to live with it (emphasis added) [11]. The instructional delivery protocol for education is important to define if we expect to sustain self-efficacy beliefs over the long term.

4.3. Methodological Limitations. Within a substantial proportion of reviewed studies $(42.9 \%)$, there was questionable data analysis techniques used. Because of this, questions remain as to the validity and reliability of findings generated from these studies. More than half of the reviewed studies (57.1\%) failed to report reliability measures for their data. Two adapted versions of the CSES were converted into different languages [38, 42], which may have attenuated the ability of items to assess intended latent constructs (despite back translation efforts aimed to prevent this from happening). As well, two of the reviewed studies [36, 37] assessed self-efficacy using a single-item survey. This is problematic, because individual items have considerable random measurement error, usually cannot discriminate among degrees of an attribute, and lack scope when measuring a complex theoretical construct [49]. Finally, most of the studies included in this paper recruited relatively small samples $(n=41$ to 189), thus limiting the external or ecological validity of study findings. Nonetheless, almost all studies (6 of 7) used random selection to assign participants to educational interventions. In addition, the reviewed studies lack longterm followup. The average length of the reviewed studies was less than five months and none of the studies assessed self-efficacy over a period longer than 12 months.

4.4. Recommendations for Future Research and Practice. More research is needed to determine whether the development of COPDSME programs enhances COPD self-efficacy among patients. From findings of this paper, it is difficult to determine how much of the variance in self-efficacy can be attributable to various COPDSME programs. Limitations in the design of the reviewed studies call into question the main findings of the studies and limit the conclusions that can be made based on the results. Sources of efficacy information were found to be present but variable in the current paper (e.g., some lacked vicarious experiences), illustrating the lack of consensus or standardization in COPDSME content [50]. Linking specific educational interventions to selfefficacy outcomes associated with specific self-management skills/behaviors is an important avenue for future research. Efforts towards customized COPDSME strategies have been explored in the literature $[48,51]$ and more should be done to explore the impact of varying sources of selfefficacy information on efficacy outcomes. As well, the depth and breadth of future interventions in COPDSME should be informed by desirable and effective instructional considerations (e.g., time, location, delivery, content, etc.).

\section{Conclusions}

While transmitting generic health knowledge is fairly easy in the Information Age, changing self-efficacy and the value patients place in tertiary prevention of chronic disease can take considerable planning and effort. Taking steps towards this difficult end is becoming increasingly essential for managing debilitating chronic diseases. After an exhaustive literature search, this paper demonstrates that only a limited number of studies have examined the effects of selfmanagement education on COPD self-efficacy. The literature in COPD management literature supports the generalized hypothesis suggested by Bandura [23], who states that, "functional limitation may be governed more by beliefs of capability than by degree of actual physical impairment" 
(page 300). COPD self-efficacy has revealed itself as an important predecessor to health effects among patients; thus, it should be measured, reported, and compared within controlled studies examining the effects of COPDSME during the disease management process.

\section{References}

[1] K. F. Rabe, S. Hurd, A. Anzueto et al., "Global strategy for the diagnosis, management, and prevention of chronic obstructive pulmonary disease: GOLD executive summary," American Journal of Respiratory and Critical Care Medicine, vol. 176, no. 6, pp. 532-555, 2007.

[2] J. Z. Reardon, S. C. Lareau, and R. ZuWallack, "Functional status and quality of life in chronic obstructive pulmonary disease," American Journal of Medicine, vol. 119, supplement 1, no. 10, pp. S32-S37, 2006.

[3] National Center for Health Statistics, "Deaths: final data for 2007," 2010, http://www.cdc.gov/nchs/fastats/lcod.htm.

[4] U.S. Department of Health and Human Services, "Healthy People 2020: Topics and Objectives," 2010, http://www.healthypeople.gov/2020/topicsobjectives2020/overview.aspx?topicid $=36$.

[5] L. Nici, "A bill of "rights" for patients with COPD: the "right" therapy for the "right" patient at the "right" time," Thorax, vol. 65 , no. 1, pp. 2-3, 2010.

[6] J. Bourbeau and J. van der Palen, "Promoting effective self-management programmes to improve COPD," European Respiratory Journal, vol. 33, no. 3, pp. 461-463, 2009.

[7] M. von Korff, J. Gruman, J. Schaefer, S. J. Curry, and E. H. Wagner, "Collaborative management of chronic illness," Annals of Internal Medicine, vol. 127, no. 12, pp. 1097-1102, 1997.

[8] R. Kessler, E. Stahl, C. Vogelmeier et al., "Patient understanding, detection experience of COPD exacerbations: an observational, interview-based study," Chest, vol. 130, no. 1, pp. 133-142, 2006.

[9] P. Hernandez, M. Balter, J. Bourbeau, and R. Hodder, "Living with chronic obstructive pulmonary disease: a survey of patients' knowledge and attitudes," Respiratory Medicine, vol. 103, no. 7, pp. 1004-1012, 2009.

[10] N. M. Clark, J. A. Dodge, M. R. Partridge, and F. J. Martinez, "Focusing on outcomes: making the most of COPD interventions," International Journal of Chronic Obstructive Pulmonary Disease, vol. 4, no. 1, pp. 61-77, 2009.

[11] J. Bourbeau, "Self-management interventions to improve outcomes in patients suffering from COPD," Expert Review of Pharmacoeconomics and Outcomes Research, vol. 4, no. 1, pp. 71-77, 2004.

[12] R. Jones, “Too little, too late-the patients' perspective on education for COPD," Chronic Respiratory Disease, vol. 4, no. 4, pp. 189-190, 2007.

[13] J. K. Wigal, T. L. Creer, and H. Kotses, "The COPD self-efficacy scale," Chest, vol. 99, no. 5, pp. 1193-1196, 1991.

[14] R. Arnold, A. V. Ranchor, M. J. L. deJongste et al., "The relationship between self-efficacy and self-reported physical functioning in chronic obstructive pulmonary disease and chronic heart failure," Behavioral Medicine, vol. 31, no. 3, pp. 107-115, 2005.

[15] R. M. Kaplan, C. J. Atkins, and S. Reinsch, "Specific efficacy expectations mediate exercise compliance in patients with COPD," Health Psychology, vol. 3, no. 3, pp. 223-242, 1984.
[16] R. M. Kaplan, C. J. Atkins, and R. Timms, "Validity of a quality of well-being scale as an outcome measure in chronic obstructive pulmonary disease," Journal of Chronic Diseases, vol. 37, no. 2, pp. 85-95, 1984.

[17] C. L. Kohler, L. Fish, and P. G. Greene, "The relationship of perceived self-efficacy to quality of life in chronic obstructive pulmonary disease," Health Psychology, vol. 21, no. 6, pp. 610614, 2002.

[18] Y. K. Scherer and L. E. Schmieder, "The role of self-efficacy in assisting patients with chronic obstructive pulmonary disease to manage breathing difficulty," Clinical Nursing Research, vol. 5, no. 3, pp. 343-355, 1996.

[19] C. P. van Schayck, M. P. M. H. Rutten-van Molken, E. K. A. van Doorslaer, H. Folgering, and C. van Weel, "Twoyear bronchodilator treatment in patients with mild airflow obstruction. Contradictory effects on lung function and quality of life," Chest, vol. 102, no. 5, pp. 1384-1391, 1992.

[20] S. B. Bentsen, B. Rokne, T. Wentzel-Larsen, A. H. Henriksen, and A. K. Wahl, "The Norwegian version of the chronic obstructive pulmonary disease self-efficacy scale (CSES): a validation and reliability study," Scandinavian Journal of Caring Sciences, vol. 24, no. 3, pp. 600-609, 2010.

[21] M. Warwick, R. Gallagher, L. Chenoweth, and J. SteinParbury, "Self-management and symptom monitoring among older adults with chronic obstructive pulmonary disease," Journal of Advanced Nursing, vol. 66, no. 4, pp. 784-793, 2010.

[22] V. S. Fan, E. M. Udris, and D. H. Au, "Factors associated with self-efficacy in COPD. Psychosocial and behavioral factors in lung disease," American Journal of Respiratory Critical Care Medicine, vol. 179, Article ID A1077, 2009.

[23] A. Bandura, Self-Efficacy: The Exercise of Control, W.H. Freeman, New York, NY, USA, 1997.

[24] A. Bandura, "Health promotion by social cognitive means," Health Education and Behavior, vol. 31, no. 2, pp. 143-164, 2004.

[25] A. Bandura, "Self-efficacy: toward a unifying theory of behavioral change," Psychological Review, vol. 84, no. 2, pp. 191-215, 1977.

[26] K. R. Lorig and H. R. Holman, "Self-management education: history, definition, outcomes, and mechanisms," Annals of Behavioral Medicine, vol. 26, no. 1, pp. 1-7, 2003.

[27] A. Bandura, "Self-efficacy mechanism in human agency," American Psychologist, vol. 37, no. 2, pp. 122-147, 1982.

[28] V. J. Strecher, B. M. deVellis, M. H. Becker, and I. M. Rosenstock, "The role of self-efficacy in achieving health behavior change," Health Education Quarterly, vol. 13, no. 1, pp. 73-92, 1986.

[29] J. M. Gormley, V. Carrieri-Kohlman, M. K. Douglas, and M. S. Stulbarg, "Treadmill self-efficacy and walking performance in patients with COPD," Journal of Cardiopulmonary Rehabilitation, vol. 13, no. 6, pp. 424-431, 1993.

[30] J. Bourbeau and D. Nault, "Self-management strategies in chronic obstructive pulmonary disease," Clinics in Chest Medicine, vol. 28, no. 3, pp. 617-628, 2007.

[31] R. Hodder, S. Kesten, S. Menjoge, and K. Viel, "Outcomes in COPD patients receiving tiotropium or salmeterol plus treatment with inhaled corticosteroids," International Journal of Chronic Obstructive Pulmonary Disease, vol. 2, no. 2, pp. 157-167, 2007.

[32] K. Lorig, A. Stewart, P. Ritter, V. Gonzalez, D. Laurent, and J. Lynch, Outcome Measures for Health Education and Other Health Care Interventions, Sage, Thousand Oaks, Calif, USA, 1996. 
[33] V. Carrieri-Kohlman, J. M. Gormley, M. K. Douglas, S. M. Paul, and M. S. Stulbarg, "Exercise training decreases dyspnea and the distress and anxiety associated with it: monitoring alone may be as effective as coaching," Chest, vol. 110, no. 6, pp. 1526-1535, 1996.

[34] H. Schuurmans, N. Steverink, N. Frieswijk, B. P. Buunk, J. J. Slaets, and S. Lindenberg, "How to measure self-management abilities in older people by self-report. The development of the SMAS-30," Quality of Life Research, vol. 14, no. 10, pp. 22152228, 2005.

[35] K. R. Lorig, D. S. Sobel, P. L. Ritter, D. Laurent, and M. Hobbs, "Effect of a self-management program on patients with chronic disease," Effective Clinical Practice, vol. 4, no. 6, pp. 256-262, 2001.

[36] A. H. T. Davis, V. Carrieri-Kohlman, S. L. Janson, W. M. Gold, and M. S. Stulbarg, "Effects of treatment on two types of self-efficacy in people with chronic obstructive pulmonary disease," Journal of Pain and Symptom Management, vol. 32, no. 1, pp. 60-70, 2006.

[37] D. Donesky-Cuenco, L. Chyall, H. Nguyen, A. Davis, and V. Carrieri-Kohlman, "Improvements in self-efficacy for walking and managing shortness of breath in patients with COPD are sustained for one year during a dyspnea self-management program," American Journal of Respiratory Critical Care Medicine, vol. 181, Article ID A1213, 2010.

[38] M. Kara and T. Asti, "Effect of education on self-efficacy of Turkish patients with chronic obstructive pulmonary disease," Patient Education and Counseling, vol. 55, no. 1, pp. 114-120, 2004.

[39] K. M. Lemmens, A. P. Nieboer, M. P. Rutten-van Mölken et al., "Application of a theoretical model to evaluate COPD disease management," BMC Health Services Research, vol. 10, article 81, 2010.

[40] Y. K. Scherer, L. E. Schmieder, and S. Shimmel, "The effects of education alone and in combination with pulmonary rehabilitation on self-efficacy in patients with COPD," Rehabilitation Nursing, vol. 23, no. 2, pp. 71-77, 1998.

[41] M. L. Stellefson, B. H. Chaney, and J. D. Chaney, "Examining the efficacy of DVD technology compared to printbased material in COPD self-management education of rural patients," Californian Journal of Health Promotion, vol. 7, pp. 26-41, 2009.

[42] K. W. Wong, F. K. Y. Wong, and M. F. Chan, "Effects of nurse-initiated telephone follow-up on self-efficacy among patients with chronic obstructive pulmonary disease," Journal of Advanced Nursing, vol. 49, no. 2, pp. 210-222, 2005.

[43] B. Thompson, Foundations of Behavioral Statistics: An Insight Based Approach, The Guilford Press, New York, NY, USA, 2006.

[44] P. Dugard and J. Todman, "Analysis of pre-test-post-test control group designs in educational research," Educational Psychology, vol. 15, no. 2, pp. 181-198, 1995.

[45] C. J. Huberty and S. Olejnik, Applied MANOVA and Discriminant Analysis, John Wiley \& Sons, Hoboken, NJ, USA, 2nd edition, 2006.

[46] Global Initiative for Chronic Obstructive Lung Disease, Global Strategy for the Diagnosis, Management, and Prevention of Chronic Obstructive Pulmonary Disease (Updated 2010), Gold Science Committee, 2010.

[47] P. B. Koff, R. H. Jones, J. M. Cashman, N. F. Voelkel, and R. W. Vandivier, "Proactive integrated care improves quality of life in patients with COPD," European Respiratory Journal, vol. 33, no. 5, pp. 1031-1038, 2009.
[48] T. L. Petty, E. C. Dempsey, T. Collins et al., "Impact of customized videotape education on quality of life in patients with chronic obstructive pulmonary disease," Journal of Cardiopulmonary Rehabilitation, vol. 26, no. 2, pp. 112-117, 2006.

[49] J. C. Nunnally and I. H. Bernstein, Psychometric Theory, McGraw-Hill, New York, NY, USA, 3rd edition, 1994.

[50] T. W. Effing, E. M. Monninkhof, P. D. L. P. M. van der Valk et al., "Self-management education for patients with chronic obstructive pulmonary disease," Cochrane Database of Systematic Reviews, no. 4, Article ID CD002990, 2007.

[51] M. L. Stellefson, B. H. Chaney, and J. D. Chaney, "Using exploratory focus groups to inform the development of targeted copd self-management education DVDs for rural patients," International Journal of Telemedicine and Applications, vol. 2010, Article ID 450418, 13 pages, 2010. 


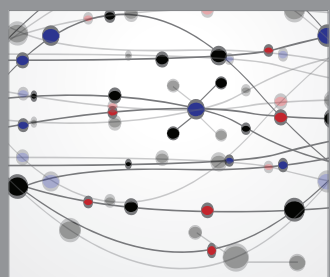

The Scientific World Journal
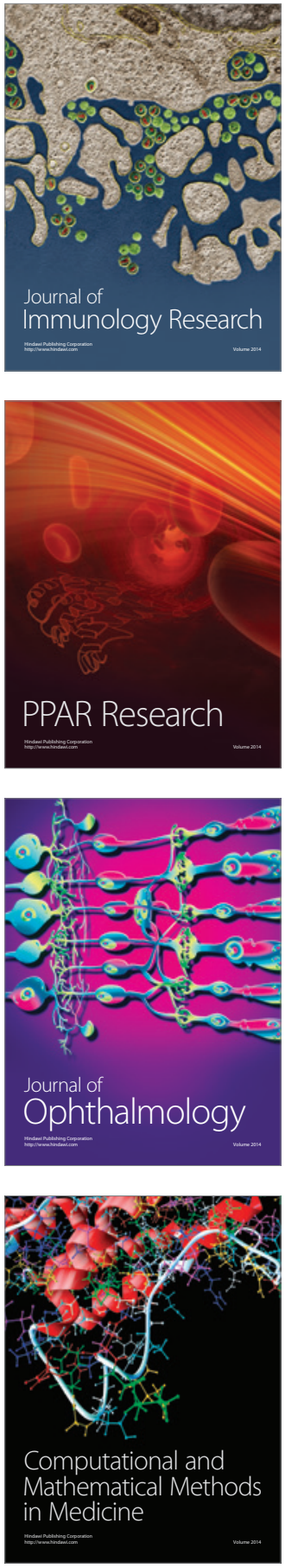

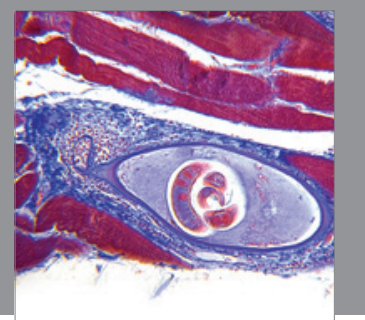

Gastroenterology

Research and Practice
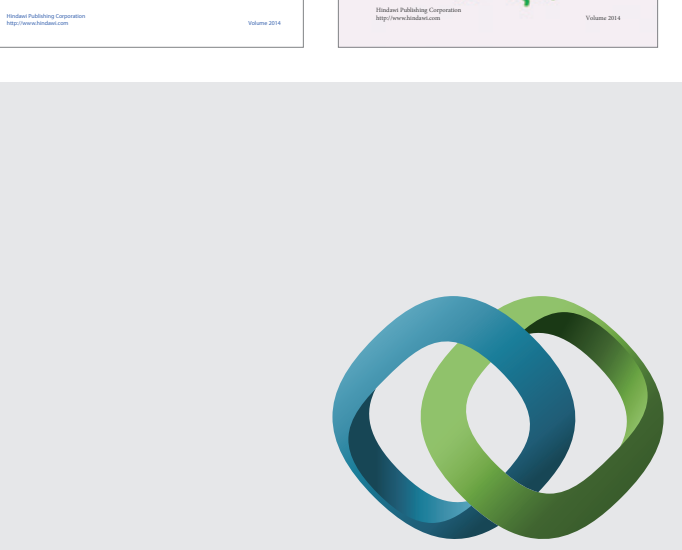

\section{Hindawi}

Submit your manuscripts at

http://www.hindawi.com
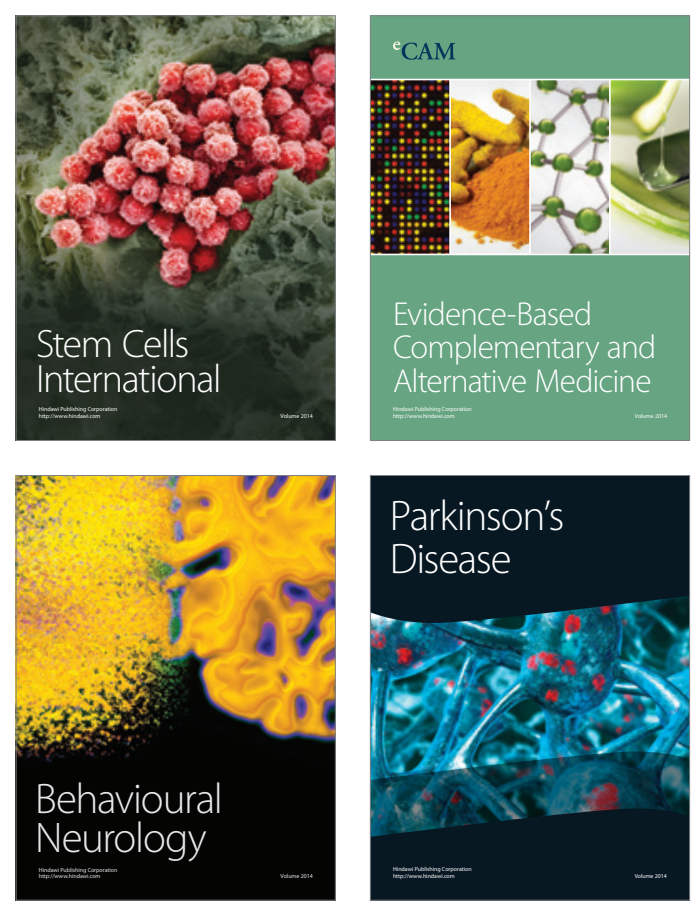

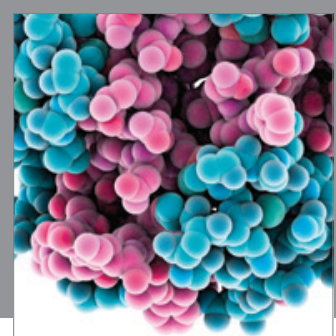

Journal of
Diabetes Research

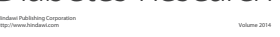

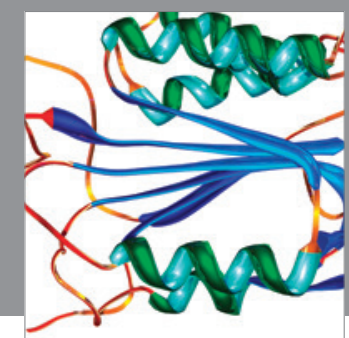

Disease Markers
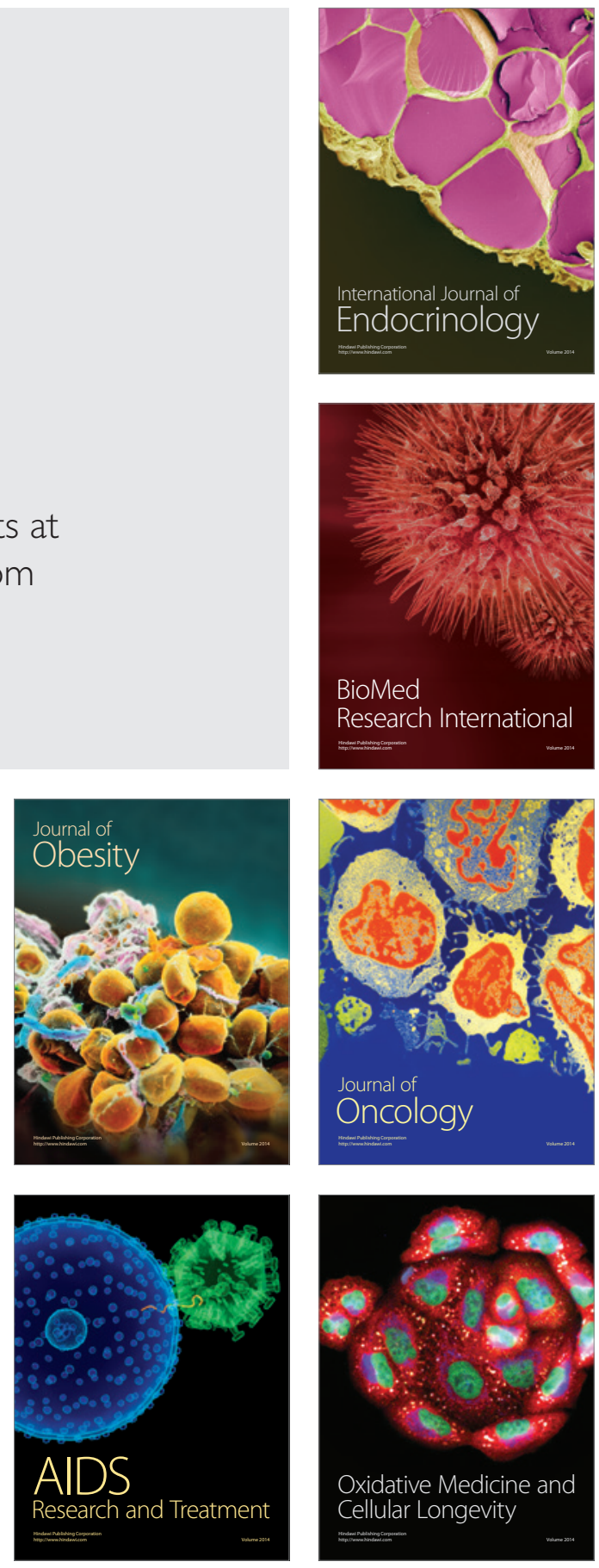